$\begin{array}{ll}\text { Kastamonu Eğitim Dergisi } & \\ \text { Kastamonu Education Journal } & \begin{array}{l}\text { Basvuru Tarihi/Received: } 14.01 .2018 \\ \text { Ocak 2019 Cilt:27 Sayı:2 } \\ \text { kefdergi.kastamonu.edu.tr }\end{array}\end{array}$

\title{
Lojistik Regresyon Analizi ile İlköğretim İkinci Kademe Öğrencilerinde İnternet Bağımlılığı ve Sosyal Beceri Düzeyi Arasındaki İlişkinin İncelenmesi
}

\section{The Analysis of the Relation Among Internet Addiction and Social Skills Level With Logistic Regression Analysis in Primary Education Second Stage Students}

\section{Öz}

\author{
Egemen HANIMOĞLU1
}

Bu çalışma, ilköğretim ikinci kademe öğrencilerinde sosyal beceri düzeyinin, cinsiyetin ve sınıf düzeyinin internet bağımlılık düzeyini yordayıp yordamadığını belirlemek için yapılmıştr. Araştırma, Adana'nın Çukurova ve Seyhan ilçelerinde 6., 7. ve 8. sınıfa devam eden, $283(\% 50,3)$ kız ve $275(\% 49,7)$ erkek olmak üzere toplam 558 öğrenci üzerinde yapılmıştır. Araştırmada verilerin toplanılması amacıyla araştırmacı tarafindan hazırlanan kişisel bilgi formu, İnternet Bağımlılık Ölçeği ve Matson Çocuklarda Sosyal Beceri Değerlendirme Ölçeği kullanılmıştı. Elde edilen veriler lojistik regresyon analizi ile incelenmiş ve sonuç olarak olumsuz sosyal davranış alt ölçeği puanlarının, cinsiyetin ve sınıf düzeyinin internet bağımlılık düzeyinin düşük ya da yüksek olmasını açıklamada anlamlı yordayıcılar oldukları belirlenmiştir.

Anahtar Kelimeler: İnternet bağımlıı̆ı̆ı, sosyal beceri, olumlu sosyal davranış, olumsuz sosyal davranış

\section{Abstract}

The purpose of this study is to determine whether the level of social skills (positive social behavior level and negative social behavior level), gender and class level predict the level of internet addiction in elementary school second level students. The sample of the study consisted of 558 students, 283 (50.3\%) female and 275 (49.7\%) boys, who continued to 6th, 7th and 8th grades in Çukurova and Seyhan districts of Adana. In the scope of the research, personal information form prepared by the researcher, Internet Addiction Scale and Matson Evaluation of Social Skills with Youngsters were used to collect data. The obtained data were analyzed by logistic regression analysis and it was determined that negative social behavior subscale scores, gender and class level were significant predictors of the low or high level of internet addiction.

Keywords: Internet addiction, social skills, positive social behavior, negative social behavior

1. Çukurova Üniversitesi, Eğitim Fakültesi, Türkçe ve Sosyal Bilimler Eğitimi Bölümü, Adana,Türkiye; https://orcid.org/0000-0001-7734-5013 


\section{Extended Summary}

Introduction : When the Internet is thought to be used more by adolescents and children, it makes adolescents and children vulnerable to the negative aspects of the Internet and significantly affects their personal, social and physical development.When the relevant literature is examined, it is observed that excessive internet use in children and adolescents is investigated in relation to different variables (eg self-esteem, academic achievement, loneliness) and in-depth information about how they affect their development (Nichols and Nicki, 2004; Niemz, Griffiths and Banyard, 2005; Kirallo, 2005; Li and Chung, 2006; Wu and Tsai, 2006; Yang and Tung, 2007; Young, 2007).

Similarly, there is a need for studies to understand how the use of excessive internet in children and adolescents results in our country. In this context, there is a limited number of researchs when the domestic literature is examined; it has been observed that studies investigating the relationship between excessive internet use and academic achievement, self-esteem and loneliness have been observed (Orhan ve Akkoyunlu, 2004; Esen, 2007). However, it is noteworthy that there is no study that examines the relationship between social skill level and internet addiction.

It is also believed that this study is important in terms of shedding light on preventive studies that are planned to combat internet addiction when excessive internet use is thought to negatively affect the personal, social and physical development of children and adolescents (Young, 2007).

The aim of this research is to determine whether the level of social skills, sex, and class level predicts the level of internet addiction in primary school second level students.

\section{Method}

Sample : The sample of the study consisted of 558 students, 283 (50.3\%) female and 275 (49.7\%) boys, who continued to 6th, 7th and 8th grades in Çukurova and Seyhan districts of Adana.

Instruments : In the scope of the research, personal information form prepared by the researcher, Internet Addiction Scale and Matson Evaluation of Social Skills with Youngsters were used to collect data.

Analysis of Data : The dependent variable of the research is "internet addiction level"; independent variables are "positive social behavior level", "negative social behavior level" and "sex" and "class level". A dual-logistic regression analysis technique was used.

Findings : When the results are examined, it is seen that 1 unit increase in sex variable leads to $\% 19.8$ increase in internet addiction odds. Similarly, the 1unit increase at the class level was \% 8.51 increase in internet addiction odds. Finally, 1 unit increase in negative social behavior sub-dimension was \% 19.9 increase in internet addiction odds. As a result, it has been determined that students who are inadequate in terms of social skills, male students, and upper-class students are in the risk group in terms of internet addiction.

Results and Discussion : When the findings were examined, it was determined that male students were in the risk group in terms of internet addiction. When the related literature is examined, it is seen that findings are parallel to the results obtained in the research (Scherer ve Bost, 1997; Akt: Griffiths, 1999; Di Nicola, 2004; Johansson ve Götestam, 2004; Cao ve Su, 2007; Morahan-Martin ve Schumacher, 2000; Balta ve Horzum, 2008).

In addition, according to the results of the research, students who exhibit negative social behaviors are also the result of the risk of internet addiction. Individuals experiencing barriers to social relations frequently resort to internets to regenerate and maintain personal relationships, and the Internet replaces face-to-face communication (Inderbiten, Walters ve Bukowski, 1997). Individuals who can not specify themselves in a correct and real way in everyday life are in an effort to establish meaningful relationships on the internet (Amichai-Hamburger, Wainapel ve Fox, 2002).

Also, as the class level of middle school students increases, the risk of being addicted to the internet increases. As the age progresses, it becomes easier to reach the internet and the students are more engaged with the internet. For this reason, the risk of being addicted to the internet is higher in upper classes. 


\section{Giriş}

İnternetin iletişim özelliği esas alınarak bakıldığında, temellerinin 19. yüzyılın ilk yarısında icat edilen telgrafa kadar dayandığını söylemek mümkündür. Günümüzde birçok farklı alanda kullanılan araçlardan biri olan ve 1876 yılında Alexander Graham Bell tarafindan icat edilen telefonla, bu iletişim şekli en iyi halini almış ve kullanım sahasını oldukça genişletmiştir. Dünyanın farklı coğrafyalarında, mekânsal uzaklık gözetmeksizin milyonlarca kullanıcının aynı anda veya farklı zamanlarda yararlanabildiği internet, bu anlamda erişim kapasitesi dikkate alındığında oldukça önemli bir iletişim ağı durumuna gelmiştir. (Yalçın, 2003: 77).

Günümüzde oldukça güçlü, etkili, hızlı bir iletişim ve bilgi paylaşım aracı olan internetin, 1962 yılında temelleri atıldığı zaman böyle bir seviyeye geleceği belki de hiç düşünülmemişti. Bilginin transferi, yüzyıllar boyunca mekânsal boyutta zorluklar taşımış, çoğu zaman insanlara ve kurumlara uzun vakitler kaybettirmiştir. İnternetle birlikte iletişim, bilgi paylaşımı, haberleşme tahmin edilemeyecek düzeyde hızlanmış, bunun yanı sıra bu iletişim aracı özellikle günümüzde neredeyse her alanda kullanılmaya başlanmıştır. Alışveriş yapma, oyun oynama, haber alma, sohbet etme ve hatta arkadaşık kurma gibi durumlar, şimdilerde bu iletişim ağı sayesinde hızlı ve aktif bir biçimde gerçekleşmekte ve bu ağ neredeyse milyonlarca kullanıcıyı barındırmaktadır. Çağımızın teknoloji ve hız çağı olduğunu kabul edersek, bu iletişim ağının önemli ölçüde olumlu yanları olduğunu da kabul etmek durumundayız. (Akınoğlu, 2002: 6-9)

Olumlu yanlarının yanı sıra, günlük yaşamın vazgeçilmez bir parçası haline gelen internetin beraberinde getirdiği olumsuz özellikler de yeni araştırmalara kapı aralamıştr. İnsanları tembelliğe, asosyalliğe itmesi, kişilerarası iletişimi zayıflatması vb. durumların artş̧yla bu iletişim ağının çift yönlü etkileri araştıılmaya başlanmıştır.

Young (1996) bu anlamda internet kullanımını DSM IV (Diagnostic and Statistical Manual of Mental Disorders)'ün kumar bağımlılığı ölçütlerini uyarlayarak yapt̆ğı araştırmayla bu alanda ilk olmuştur. Bu araştırmayla birlikte internet bağımlılığı üzerine birçok çalışma yapılmış ve çeşitli testler geliştirilmiştir. Bunlardan biri İnternette Bilişsel Durum Ölçeği (IBDÖ, Online Cognition Scale)'ni geliştiren Davis (2001)'tir. Davis bilişsel-davranış̧̧ı yaklaşımla internet bağımlılığı kavramını genişletmeye çalışmıştır. Patolojik Internet Kullanımı (PiK) olarak adlandırılan davranışı inceleyen Morahan-Martin ve Schumacher (2000) ise Pík'i 13 maddelik bir ölçek ile değerlendirmiştir. Bu ölçeğe göre dört ya da daha fazla olumlu yanıt verenler patolojik internet kullanıcıları (Pi kullanıcılar) olarak tanımlanmışlardır. Bunların yanı sıra Genellenmiş Problemli İnternet Kullanım Ölçeği (Generalized Problematic Internet Use Scale)'ni literatüre kazandıran Caplan (2002) gibi birçok araştırmacı da internet bağımlılığını ölçmeye yönelik çeşitli yöntemler geliştirmiş, bu konu üzerine çalışmalarda bulunmuşlardır. Nichols ve Nicki (2005), Yellowless ve Marks (2005) internetin hangi taraflarının böyle bir bağımlılığa yol açtığını araştırmış; Lin ve Tsai (2003), Chak ve Leung (2004), Praterelli ve Koch (2004) internet bağımlılarının benlik özellikleri üzerine yoğunlaşmış, kişilerin psikolojileriyle derinden ilgilenmişlerdir. Yapılan çalışmalar bu kavramla ilgili birçok önemli veriyi kapsarken, aynı zamanda sonraki çalışmalara da öncü olmaktadır.

Ülkemizde bu iletişim ağından kaynaklı bağımlılık üzerine, 2000'li yıllarda ilginin ve çalışmaların yoğunlaştığı görülür. Bayraktar (2001) internet bağımlılığına ergen gelişimi açısından bakmış ve günümüzde de sıkça değinilen bu durumla ilgili çalışmalar yapmıştır. Bunun yanı sıra Ayaroğlu (2002) çalışmalarında daha çok kız ve erkek üniversite öğrencilerine yoğunlaşmış, onların internet kullanımları ile yalnızlık düzeyleri arasındaki ilişkiyi incelemiştir. Bu gibi çalışmalar bize önemli veriler sunarken, yıllar geçtikçe bu iletişim ağının güçlenmesiyle doğru orantılı olarak yapılan çalışmalarda da arţ̧̧ görülmüştür. Sevindik (2003) ve Bölükbaşı (2003) bu durumla ilgili internet kafelerin etkisini incelerken, Yaşar ve Ersoy (2003), Orhan ve Akkoyunlu (2004) ise ilköğretim öğrencilerinin internet bağımlılıklarıyla ilgilenmiştir. Farklı düzeylerdeki kullanıcıların, farklı derecede internet kullanımına ihtiyaç duydukları göz önüne alınırsa, çalışmaların da bu doğrultuda çeşitlilik göstermesi beklenilen bir durumdur. İnternet Bilişsel Durum Ölçeği (iBDÖ) (Online Cognition Scale-OCS)'nin geçerlilik ve güvenirliğini incelemek amacıyla bir çalışma yürüten Özcan ve Buzlu (2005), yapılan çalışmaların ne denli dikkate değer olduğunun vurgulanması anlamında önemlidir. Yalçın (2003) bu konuya sosyolojik olarak yaklaşırken, Esen (2007) akran baskısıyla internet bağımlılığı ilişkisini ve ayrıca algılanan sosyal destek değişkenlerini de göz önüne alarak bu durumun etkisini incelemiştir.

Günümüzde çocuklarda ve ergenlerde internet kullanımı oldukça yaygınlaştı̆̆ı için büyük önem taşımaktadır. Bu alanda aktif olarak en fazla bu grubun bulunduğu düşünülürse, olumlu ve olumsuz anlamda etki altna girenler de çocuklar ve ergenler olacaktır. Onların her anlamda gelişimini etkileyen bu iletişim ağı, verimli ve uygun seviyede kullanılmadığı takdirde oldukça önemli problemlere yol açmakla birlikte, dolaylı olarak toplumsal yapıda da olumsuzluklara yol açacaktır.

Bireylerin kişisel, sosyal, fiziksel gelişimlerini önemli derecede etkileyen internet kullanımının, benlik saygısı, akademik başarı, yalnızlık gibi farklı değişkenlerle ilişkisi ve bireylerin gelişimine ne derecede etkide bulunduğu üzerine birçok 
çalışma yapılmıştır (Nichols ve Nicki, 2004; Niemz, Griffiths ve Banyard, 2005; Kirallo, 2005; Li ve Chung, 2006; Wu ve Tsai, 2006; Yang ve Tung, 2007; Young, 2007).

Internet kullanımının çocuklarda ve ergenlerde gerekli ve uygun ölçüde olup olmadığının incelenmesi, ülkemizde önemli çalışmalarla göz önüne serilmiş olmakla birlikte, bazı değişkenlerle olan ilişkilerin araştrılmasında eksiklikler de görülmektedir. Ülkemizde aşırı internet kullanımının akademik başarı, yalnızıık, benlik saygısı gibi değişkenlerle olan ilişkisi ile ilgili araştırmalar bulunmaktadır (Orhan ve Akkoyunlu, 2004; Esen, 2007). Buna karşın oldukça önemli bir değişken olan sosyal beceri düzeyi ile ilgili bir ilişkiyi inceleyen herhangi bir çalışma olmadığı görülmektedir. Bu anlamda internet bağımlıı̆̆̆ ile sosyal beceri düzeyi arasındaki ilişkinin tanımlanması ve dolayısıyla veriler elde edilip çözüm önerileri sunulması da bu anlamda eksik kalmaktadır.

Aşırı internet kullanımının çocuklarda ve ergenlerde oldukça önemli olumsuz etkilerini de düşündüğümüz zaman (Young, 2007), bu gibi çalışmaların eksikliği sebebiyle, internet bağımlılı̆ı ile mücadelede planlanacak önleyici çalışmalar da sekteye uğrayacaktır. Dolayısıyla bu önleyici çalışmalara ışık tutması açısından yapılan bu araştırmanın önemli olduğu düşünülmektedir.

Bu bilgiler ışığında, araştırmanın amacı, ilköğretim ikinci kademe öğrencilerinde sosyal beceri düzeyinin (olumlu sosyal davranış düzeyi ve olumsuz sosyal davranış düzeyi), cinsiyetin ve sınıf düzeyinin internet bağımlılık seviyesini yordayıp yordamadığını belirlemektir.

\section{Yöntem}

\section{Örneklem}

Bu araştırmada ilişkisel tarama modeli kullanıımıştır. Araştırma, Adana'nın Çukurova ve Seyhan ilçelerinde bulunan Sıtkı Kulak İlköğretim Okulu, Adana Genç i̧̧̇ Adamları Derneği (AGIAD) İlköğretim Okulu, Özel Başkent Illköğretim Okulu ve Özel Ada-Fen Okulları'nda 6, 7 ve 8. sınıfa devam eden, $283(\% 50,3)$ kız ve $275(\% 49,7)$ erkek olmak üzere toplam 558 ile gerçekleştirilmiştir. Çalışmaya katılan öğrenciler 12 ile 14 yaşları arasında olup yaş ortalamaları 12,96 standart sapması 0.79 'dur. Okullar ve dershane, ulaşılabilir örnekleme yöntemine göre belirlenmiştir.

\section{Veri Toplama Araçları}

Öğrencilerin internet bağımlılık düzeyine ilişkin veriler "Internet Bağımlılık Ölçeği” (Bayraktar, 2001), sosyal beceri düzeylerine ilişkin veriler "Matson Çocuklarda Sosyal Beceri Değerlendirme Ölçeği” (Bacanlı ve Erdoğan, 2003) ve demografik değişkenlere iliş̧in veriler araştırmacı tarafindan hazırlanan "Kişisel Bilgi Formu" kullanılarak elde edilmiştir.

\section{Kişisel Bilgi Formu}

Araştırmacı tarafindan düzenlenen kişisel bilgi formunda, öğrencilerin cinsiyetini, sınıf düzeyini belirlemeye yönelik sorular yer almaktadır.

\section{İnternet Bağımlılık Ölçeği (їB̈)}

Young (1996) tarafindan, DSM-IV'ün “Patolojik Kumar Oynama” ölçütlerinden uyarlanarak oluşturulan "Tanı Anketi” daha sonra geliştirilmiş ve 20 soruluk bir İnternet Bağımlılık Ölçeği oluşturulmuştur.

Young'ın başını çektiği “internet Bağımlılık Merkezi'nin http://www.netaddiction.com” adresinden de ulaşılabilen bu test bir kendi kendini değerlendirme (self report) testi olup, genellikle yukarıda belirtilen internet adresine ulaşanların kendilerini değerlendirebilecekleri bir şekilde hazırlanmıştı. Likert tipi bir ölçek olan İnternet Bağımlılık Ölçeği'nde katılımcıdan "hiçbir zaman", "nadiren", "arada sırada", "çoğunlukla", "çok sık" ve "devamlı" seçeneklerinden birini işaretlemesi istenmektedir.

Bu seçeneklere sırasıyla 0,1,2,3,4 ve 5 puan verilmektedir. 80 ve üzeri puan alanlar "internet bağımlısı" olarak tanımlanmaktadır. 50-79 puan arası alanlar "sınırlı semptom gösterenler", "50 puan ve alt " alanlar "semptom göstermeyenler" olarak tanımlanmıştır.

Bayraktar (2001) tarafindan İngilizce'den Türkçe'ye çevrilen ölçek, Ege Üniversitesi Edebiyat Fakültesi Psikoloji Anabilim dalındaki beş öğretim görevlisi tarafindan incelenmiş ve sorular anlam bütünlüğünü bozmayacak şekilde 12-17 yaş grubu ergenlerin anlayabileceği şekilde uyarlanmıştır.

Çeviri testin standardize edilmiş Alpha değeri açısından güvenirliği .91, Spearman - Brown değeri açısından da 0.87 'dir. Bu sonuçlar testin güvenilir olduğunu düşündürmektedir (Bayraktar, 2001: 90). Ayrıca bu çalışmada ölçeğin 
güvenirlik için Cronbach Alpha katsayısı 0.89 olarak hesaplanmıştır.

\section{Matson Çocuklarda Sosyal Beceri Değerlendirme Ölçeği}

Matson Çocuklarda Sosyal Becerileri Değerlendirme Ölçeği, 12-14 yaş arası çocukların sosyal becerilerini değerlendirmek amacıyla hazırlanmış, toplam 47 maddeden oluşan 5'li likert tipinde bir ölçektir. Matson, Rotatory ve Hessel tarafindan 1983 yılında geliştirilmiş olan ölçek, sözel ve sözel olmayan sosyal ve saldırgan davranışları ölçmektedir.

Ölçeğin öğretmen ve öğrenci formları bulunmaktadır. Öğrenci formu 62, öğretmen formu da 64 maddeden oluşmaktadır. Türkçe'ye uyarlanan form 62 maddelik öğrenci formudur. Bu ölçeğin toplam 5 faktörü bulunmaktadır. Bunlar; (1) uygun sosyal beceriler, (2) uygun olmayan atlganlık, (3) fevrilik, (4) kendine güven ve (5) kıskançlık/içekapanıklıktır (Bacanlı ve Erdoğan, 2003).

Matson Çocuklarda Sosyal Becerileri Değerlendirme Ölçeği, Bacanlı ve Erdoğan (2003) tarafindan Türkçe'ye uyarlanmıştr. Ölçeğin Türkçe'ye uyarlama çalışmaları 12-14 yaşları arasında 89'u erkek, 91'i kız; toplam 180 öğrenci üzerinde yürütülmüştür. Bulgular bu ölçme aracının 12-14 yaş çocuklarının sosyal becerilerini değerlendirmede yeterli düzeyde geçerli ve güvenilir olduğunu göstermektedir.

Yapılan faktör analizi sonucundan ölçeğin maddelerinin, orijinalinden farklı olarak, 2 faktörde toplandığı görülmüştür. Faktör yükü 0.30'dan düşük maddeler çıkartılmış ve sonuçta ölçeğin 47 maddelik son haline ulaşılmıştır. Elde edilen iki faktörden ilki "olumsuz sosyal davranışlar", ikincisi ise "olumlu sosyal davranışlar" şeklinde adlandırılmıştır (Bacanlı ve Erdoğan, 2003).

Bacanlı ve Erdoğan (2003) benzer ölçek geçerliği için Sosyal Beceri Ölçeği ve Öğretmen Dereceleme Formunu kullanmış ve bu iki değerlendirme aracı ile Matson Çocuklarda Sosyal Becerileri Değerlendirme Ölçeği arasında ilişki olup olmadığı incelenmiştir. Sonuçlar "olumsuz sosyal davranışlar" alt ölçeği ile Sosyal Beceri Ölçeği arasında düşük düzeyde bir ilişki olduğunu ancak, "olumlu sosyal davranışlar" alt ölçeği ile Sosyal Beceri Ölçeği arasında ise orta düzeyde bir ilişki olduğunu göstermektedir.

Bacanlı ve Erdoğan (2003), Matson Çocuklarda Sosyal Becerileri Değerlendirme Ölçeği'nin test tekrar test güvenirlik katsayısını "olumsuz sosyal davranışlar" alt ölçeği için 0.70 , "olumlu sosyal davranışlar" alt ölçeği için 0.74 ve toplam puan için ise 0.77 olarak belirlemiştir. Ölçekte yer alan 41 maddenin madde toplam puan korelasyonlarının 0.30 'un üstünde olduğu belirlenmiştir.

Ölçeğin Cronbach Alpha iç tutarlıık katsayıları "olumsuz sosyal davranışlar" alt ölçeği için 0.68, "olumlu sosyal davranışlar" alt ölçeği için 0.74 ve toplamı için ise 0.85 olarak bulunmuştur. Ölçeğin puanlandırılması "bana hiç uygun değil" 1 puan; "bana pek uygun değil" 2 puan; "bana biraz uygun" 3 puan; "bana oldukça uygun" 4 puan; "bana tamamen uygun" 5 puan şeklinde yapılmaktadır. Ölçekten alınabilecek en düşük puan 47, en yüksek puan ise 235'tir. Ölçekte olumlu sosyal davranışlar ve olumsuz sosyal davranışlar olarak iki alt boyut bulunmaktadır (Bacanlı ve Erdoğan, 2003). Bu çalışmada ölçeğin olumlu sosyal davranışlar alt ölçeği için Cronbach Alpha katsayısı 0.80 , olumsuz sosyal davranışlar alt ölçeği için 0.74 ve toplam puan için 0.82 olarak hesaplanmıştir

\section{Verilerin Analizi}

Araştırmada internet bağımlılık düzeyi (internete bağımlı, internete bağımlı değil) bağımlı değişken; sosyal beceri düzeyinin alt boyutları olan "olumlu sosyal davranış düzeyi (alt boyut)" ve "olumsuz sosyal davranış düzeyi (alt boyut)" ile "cinsiyet" ve "sınıf düzeyi" bağımsız değişken olarak alınarak lojistik regresyon analizi uygulanmıştır.

Verilerin analizinde bağımlı değişken olan internet bağımlık düzeyinin normal dağıım gösterip göstermediği araştrıımış ve normal dağılım göstermediği saptanmıştır. Bu nedenle “Internet Bağımlılık Ölçeği”nden elde edilen puanlar yüksek ve düşük olarak gruplandırılırken, gruplamanın uç değerlerden etkilenmesini engellemek için ortalama ve standart sapma değil ortanca ve çeyrek sapma değerleri kullanılmış ve bu nedenle ortanca değerinin 1 çeyrek sapma alt ve üstü değerler bulunarak analize dahil edilmiştir. 


\section{Bulgular}

Araştırmaya katılan ilköğretim ikinci kademe öğrencilerinin internet bağımlısı olmalarını ve olmamalarını olumlu sosyal davranış düzeyinin, olumsuz sosyal davranış düzeyinin, cinsiyetin ve sınıf düzeyinin ne derece yordadığını belirlemek amacıyla lojistik regresyon analizi tekniği kullanılmıştır.

Araştırmadan elde edilen bulgulara göre, ilköğretim ikinci kademe öğrencilerinin olumsuz sosyal davranış alt ölçeğinden aldıkları puanların, cinsiyetin ve sınıf düzeyinin internet bağımlılık düzeyinin düşük ya da yüksek olmasını açıklamada anlamlı yordayıcılar oldukları belirlenmiştir. $(X 2=125.126, s d=4, N=281, p<.001)$. Yordayıcı değişkenler toplam varyansın \% 48 'ini açıklamaktadır.

Hosmer ve Lemeshow testi sonucunda internet bağımlık düzeyi açısından yüksek düzeyde bulunan ve bulunmayan öğrencilerin gözlenen ve beklenen frekansları arasında anlamlı fark olmadığı belirlenmiştir ( $p>.05)$. Bu sonuç model veri uyumunun yeterli düzeyde olduğunu göstermektedir.

Lojistik regresyon analizi sonucunda, kurulan modelin internet bağımlılık düzeyi düşük olan 127 öğrenciden 98 'ini (\%77.2), internet bağımlılık düzeyi yüksek olan 154 öğrenciden 127'sini (\%82.5) doğru olarak sınıflandırdığı belirlenmiştir. Toplam 281 öğrenciye ilişkin verilere uygulanan lojistik regresyon analizi uyumlu sonuçlar vermiş ve \%80.1 düzeyinde verileri başarıyla sınıflandırmıştır.

Tablo 1. Olumlu Sosyal Davranış Düzeyinin, Olumsuz Sosyal Davranış Düzeyinin, Sınıf Düzeyinin ve Cinsiyetin İnternet Bağımlılı̆ını Yordamaya ilişkin Lojistik Regresyon Analizi Sonuçları

\begin{tabular}{lcccccc}
\hline Değişkenler & B & Standart Hata & Wald & Sd & $P$ & $\operatorname{Exp}(\beta)$ \\
\hline Cinsiyet & 1.092 & 0.323 & 11.436 & 1 & 0.001 & 2.981 \\
Sınıf Düzeyi & 0.616 & 0.191 & 10.398 & 1 & 0.001 & 1.851 \\
Olumsuz Sosyal Davranış Düzeyi & 0.130 & 0.018 & 50.883 & 1 & 0.000 & 1.139 \\
Olumlu Sosyal Davranış Düzeyi & -0.005 & 0.011 & 0.165 & 1 & 0.685 & 0.995 \\
Sabit & -7.502 & 1.684 & 19.833 & 1 & 0.000 & 0.001 \\
\hline
\end{tabular}

Lojistik regresyon analizi modelinde yer alan her bir değişkene ait katsayıların ayrı ayrı önem kontrolünü yapabilmek için Wald testi istatistiği sonuçlarından yararlanılmıştı. Tablo 1'de yer alan Wald testi istatistik sonuçlarına bakıldığında, cinsiyet, sınıf düzeyi ve sosyal beceri düzeyinin alt boyutlarından "olumsuz sosyal davranışlar" değişkenlerinin internet bağımlıık düzeyinin yüksek düzeyde bulunmasını açıklamada anlamlı katkılar yapan değişkenler oldukları belirlenmiştir.

Tablo 1'deki sonuçlar incelendiğinde cinsiyet değişkenindeki 1 birimlik artışın (kızdan erkeğe doğru), internet bağımlısı olma odds'unda \%19,81; sınıf düzeyindeki 1 birimlik artışın internet bağımlısı olma odds'unda \%8.51; olumsuz sosyal davranış alt ölçeğindeki 1 birimlik artşın ise internet bağımlısı olma odds'unda \%13,9'luk bir artışa yol açtı̆ı görülmektedir. Yani öğrencilerin cinsiyeti bilinirse $\% 19,81$ olasılıkla; eğer sınıf düzeyi bilinirse $\% 8,51$ olasılıkla ve son olarak da olumsuz sosyal davranış düzeyi bilinirse $\% 13,9$ olasılıkla internet bağımlısı olduğu yordanabilir.

\section{Tartışma ve Sonuç}

Elde edilen bulgular incelendiğinde erkek öğrencilerin internet bağımlısı olma açısından risk grubunda oldukları belirlenmiştir. Bu çalışmada elde edilen sonuçlar daha önce yapılmış çalışmalar ile benzerlik göstermektedir (Scherer ve Bost, 1997; Akt: Griffiths, 1999; Di Nicola, 2004; Johansson ve Götestam, 2004; Cao ve Su, 2007; Morahan-Martin ve Schumacher, 2000; Balta ve Horzum, 2008). Bunun nedeni, erkeklerin internette online oyunlar oynama gibi aktivitelerle daha fazla ilgili olmalarıdır (Bruckman, 1992; Turkle, 1995; Akt: Pawlak, 2002). Toplumsal cinsiyet rolleri açısından düşünüldüğünde, genellikle erkeklerin internet kafe gibi yerlerde daha fazla vakit geçirmeleri normal karşılanmaktadır. Ayrıca erkeklerin teknolojiye daha fazla ilgi duyuyor olması da bu sonuca yol açmış olabilir. Ancak son yıllarda internet kullanımının hızla yaygınlaşıyor olması nedeniyle, internet bağımlısı olma açısından cinsiyetler arasındaki farkın yeniden incelenmesi gereklidir.

Olumsuz sosyal davranışlar sergileyen öğrencilerin de internet bağımlısı olma riski taşıdığı sonucuna ulaşılmıştır. Sosyal beceri, sosyal çevreye uyum sağlama ve uygun iletişim yolları kullanarak, oluşabilecek çatışmalarla başa çıkabil- 
me şeklinde tanımlanmaktadır (Matson, Matson ve Rivet, 2007). Sosyal ilişkilerinde engeller yaşayan bireyler, kişisel ilişkilerini yeniden oluşturmak ve sürdürmek için sıklıkla internete başvurmakta ve interneti yüz-yüze iletişimin yerine koymaktadır (Inderbiten, Walters ve Bukowski, 1997). Bu bireyler, kişilerarası ilişki gereksinmelerini gidermek ve alternatif sosyal kanallar oluşturmak için internete bağımlı hale geliyor olabilirler (Papacharissi ve Rubin, 2000). Birçok insan gerçek yaşamlarında bulamadıkları kişilerarası ilişkilerin sağladığı doyumu, internetten elde etmeye çalışmaktadır (Kraut, Patterson, Lundmark, Kiesler, Mukopadhyay ve Scherlis, 1998). Günlük yaşamda kendini doğru, gerçek bir biçimde belirtemeyen bireyler, internet ortamında anlamlı ilişkiler kurma çabası içine girmektedir (Amichai-Hamburger, Wainapel ve Fox, 2002).

Ayrıca ortaokul öğrencilerinde sınıf düzeyi arttıç̧a internet bağımlısı olma riski artmaktadır. Yaş ilerledikçe internete ulaşmak daha kolay olmakta ve öğrenciler internetle daha fazla meşgul olmaktadırlar. Bu nedenle internet bağımlısı olma riski üst sınıflarda daha yüksektir.

Sonuç olarak, bu araştırmadan elde edilen bilgilere göre sosyal becerisi düşük öğrencilerin, kızlara göre erkek öğrencilerin ve daha üst sınıftaki öğrencilerin internet bağımlılığı konusunda risk grubunda oldukları bulunmuştur.

Okullarda çalışan psikolojik danışmanlar, bu araştırmadan elde edilen sonuçları da göz önünde bulundurarak risk grubundaki öğrencileri tespit edip önleyici müdahalelerde bulunabilirler. Ayrıca, bu araştırmada bağımsız değişkenler, internet bağımlılığını her ne kadar yorduyor olsa da internet bağımlılığını yordayan diğer değişkenleri belirlemek internet bağımlılı̆ı ile başa çıkmada büyük önem taşımaktadır.

\section{Kaynakça}

Akınoğlu, O. (2002). Eğitim ve sosyalleşme açısından internet kullanımı: İstanbul örneği. Sakarya Üniversitesi Sosyal Bilimler Enstitüsü Sosyoloji Ana Bilim Dalı. Yayınlanmamış Doktora Tezi.

Amichai-Hamburger Y, Wainapel G, Fox S.(2002). On the Internet No one Knows I'm an Introvert: Extroversion, Neuroticism, and Internet Interaction. Cyberpsychol Behav, 5:125-128.

Ayaroğlu, N.S. (2002). The relationship between internet use and loneliness of university students. Orta Doğu Teknik Üniversitesi Eğitim Bilimleri Bölümü. Yayımlanmamış Yüksek Lisans Tezi, Ankara.

Bacanlı H., Erdoğan F. (2003). Matson Çocuklarda Sosyal Becerileri Değerlendirme Ölçeği'nin (MESSY) Türkçe’ye Uyarlanması. Kuram ve Uygulamada Eğitim Bilimleri Dergisi, 3( 2), 351-379.

Balta, Ö. Ç. ve Horzum, M. B. (2008). Web Tabanlı Öğretim Ortamındaki Öğrencilerin İnternet Bağımlılığını Etkileyen Faktörler. Ankara Üniversitesi Egitim Bilimleri Fakültesi Dergisi, 41(1); 185-203.

Bayraktar, F. (2001). Internet kullanımının ergen gelişimindeki rolü. Yayınlanmamış Yüksek Lisans Tezi, Ege Üniversitesi Sosyal Bilimler Enstitüsü, İzmir.

Bölükbaş, K. (2003). Internet kafeler ve internet bağımlılı̆ı üzerine sosyolojik bir araştırma: Diyarbakır örneği. Dicle Üniversitesi Sosyal Bilimler Enstitüsü Sosyoloji Ana Bilim Dalı. Yayımlanmamış Yüksek Lisans Tezi, Diyarbakır.

Cao, F. ve Su, L. (2007). Internet Addiction Among Chinese Adolescents: Prevalence and Psychological Features. Child Care Health Development, 33(3); 275-81.

Chak, K. ve Leung, L. (2004). Shyness and locus of control as predictors of internet addiction and internet use. Cyberpsychology \& Behavior, 7 (5), 559-570.

Davis, R.A. (2001). A Cognitive-behavioral model of pathological internet use. Computers in Human Behavior, 17, $187-195$.

DiNicola, M. D. (2004). Pathological internet use among college students: The prevalence of pathological internet use and its correlates. Doctoral Dissertation. Ohio University.

Ersoy, A. ve Yaşar, Ş. (2003). İlköğretim 4. ve 5. sınıf öğrencilerinin internet kullanma durumları. Türk Eğitim Bilimleri Dergisi, 1 (4), 401- 425.

Esen, K. N. (2007). Akran baskısı ve algılanan sosyal destek değişkenlerine göre, ergenlerde internet bağımlıı̆ının yordanması. Ülkemizde bağımlııkla ilgili gelişmeler içinde (ss.1-9). I. Uluslararası Bağımlılık Kongresi İstanbul.

Greenfield, D. (1999). Virtual Addiction: Help for Netheads, Cyberfreaks, And Those who Love Them, New Harbinger Publications, online: http://www.virtual-addiction.com/chapter1.htm.

Griffiths, M. (2000). Does internet and computer "addiction" exist? Some case study evidence. CyberPsychology \& Behavior, 3 (2); 211-218.

Inderbiten HM, Walters KS, Bukowski AL. (1997). The role of social anxiety in adolescent peer relations: Differences among sociometric status groups and rejected subgroups. J Clin Child Psychol, 26:338-348.

Johansson, A. ve Götestam, K. G. (2004). Internet addiction: Characteristics of a questionnaire and prevalence in Norwegian youth (12-18 Years). Scandinavian Journal Of Psychology, 45; 223-229. 
Kirallo, L.V. (2005). Internet addicition disorder: a descriptive study of colege counselors in four year institutions. University of La Verne College of Education and Organizational Leadership. Yayımlanmamış Doktora Tezi, Amerika.

Koch, W.H. ve Pratarelli, M.E. (2004). Effects of Intro/extraversion and sex on social internet use. North American Journal of Psychology, 6 (3), 371-382.

Kraut R, Patterson M, Lundmark V, Kiesler S, Mukopadhyay T, Scherlis W. (1998). Internet paradox: A social technology that reduces social involvement and psychological well-being? Am Psychol; 53:1017-1031.

Kubey RW, Lavin MJ, Barrows JR. (2001). Internet use and collegiate academic performance decrements: Early findings. J Communication; 51:366-382.

Li, S. M. ve Chung, T. M. (2006). Internet function and internet addictive behavior. Computers in Human Behavior, 22, $1067-1071$.

Matson, J. L., Matson, M. L., \& Rivet, T. T. (2007). Social skills treatments with children with autism spectrum disorders. Behavior Modification, 31, 682-707.

Morahan-Martin, J. ve Schumacher, P. (2000). Incidence and correlates of pathological internet use among college students. Computers in Human Behavior, 16; 13-29.

Nichols, L. A. ve Nicki, R. (2004). Development of a psychometrically sound internet addiction scale: a preliminary step. Psychology of Addictive Behaviors, 18 (4), 381- 384.

Niemz, K., Griffiths, M. ve Banyard, P. (2005). Prevalence of pathological Internet use among university students and correlations with self-esteem, the general health questionnaire (ghq), and disinhibition. Cyberpsychology \& Behavior, 8 (6), $562-570$.

Orhan, F. ve Akkoyunlu, B. (2004). İlköğretim öğrencilerinin internet kullanımları üzerine bir çalışma. Hacettepe Üniversitesi Eğitim Fakültesi Dergisi, 26, 107-116.

Özcan, N. ve Buzlu, S. (2005). Problemli internet kullanımını belirlemede yardımcı bir araç: “internet Bilişsel Durum Ölçeği”nin üniversite öğrencilerinde geçerlik ve güvenirliği. Bağımlılık Dergisi, 6 (1), 19-26.

Papacharissi Z, Rubin AM. (2000). Predictors of internet use. J Broadcast Electron Media, 44:175-196.

Pawlak, C. (2002). Correlates of Internet use and addiction in adolescents. Dissertation Abstracts International Section A: Humanities \& Social Sciences, 63(5-A), pp. 1727.

Sevindik, T. (2003). İnternet kafeye giden bireylerin internet kafelerden beklenti düzeyleri, internet ve internet kafeleri kullanma amaçlarının belirlenmesi: Elazığ ili örneği. Fırat Üniversitesi Sosyal Bilimler Enstitüsü Eğitim Bilimleri Ana Bilim Dalı. Yayımlanmamış Yüksek Lisans Tezi, Elazığ.

Taçyıldız, Ö. (2010). Lise öğrencilerinin internet bağımlılığı düzeyinin bazı değişkenlere göre yordanması. Yayınlanmamış Yüksek Lisans Tezi, Ege Üniversitesi Sosyal Bilimler Enstitüsü, İzmir.

Tsai, C. ve Lin, S. J. (2001). Analysis of attitudes toward computer networks and internet addiction of Taiwanese adolescents. Cyberpsychology \& Behavior, 4 (3), 373-376.

Wu, Y-T. ve Tsai, C.C. (2006). University students internet attitudes and internet self-efficacy: a study at three universities in Taiwan. Cyberpsychology \& Behavior, 9 (4), 441-450.

Yalçın, C. (2003). Sosyolojik bir bakış açısıyla internet. Cumhuriyet Üniversitesi Sosyal Bilimler Dergisi, 27 (1), 77-89.

Yang, S-C. ve Tung, C.-J. (2007). Comparison of internet addicts and non-addicts in Taiwanese high school. Computers in Human Behavior, 23, 79-96.

Yellowlees, P. M. ve Marks, S. (2007). Problematic internet use or internet addiction? Computers in Human Behavior, 23, 14471453.

Young, K. (1996). Internet Addiction: The Emergence Of A New Clinical Disorder. CyberPsychology and Behavior, 1(3), $237-244$.

Young, K. (2007). Cognitive Behavior Therapy with Internet Addicts: Treatment Outcomes and Implications. CyberPsychology and Behavior, 10(5), 671-679. 